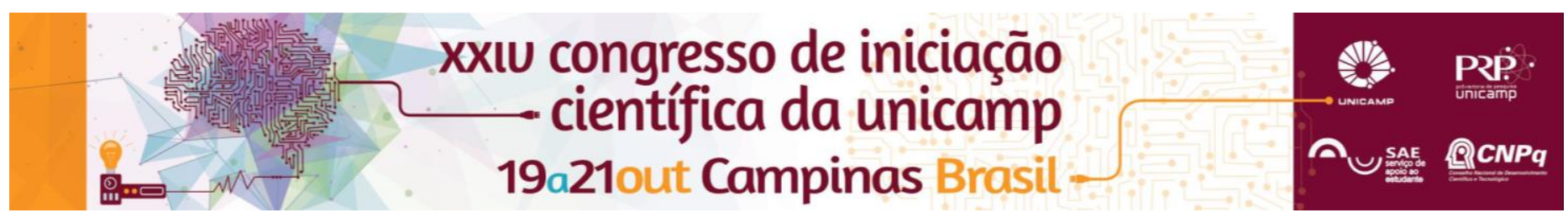

\title{
Inventário de Gases de Efeito Estufa no Campus 1 da UNICAMP em Limeira, SP.
}

\author{
Priscila B. Gonçalves*, Simone A. Pozza.
}

\section{Resumo}

O Inventário de gases de efeito é uma ótima ferramenta para quantificar a emissão de gases de efeito estufa de cada tipo de atividade. $O$ presente trabalho quantifica as emissões geradas pelo Campus 1 da UNICAMP em Limeira.

Palavras-chave:

Gases de Efeito Estufa, GHG Protocol,Inventário.

\section{Introdução}

As mudanças climáticas atualmente vêm se acentuando e se tornando um grande problema mundial. A elevada quantidade de gases de efeito estufa (GEE) que é liberada por atividades antrópicas tem agravado um processo natural chamado efeito estufa. Com o objetivo de identificar as fontes poluidoras e quantificar as emissões, o presente trabalho mostra um Inventário de Gases de Efeito Estufa no Campus 1 da UNICAMP de Limeira no ano de 2015, utilizando a metodologia do GHG Protocol. Para a elaboração do Inventário, as fontes de emissão são divididas em: Escopo 1 (emissões de GEE de fontes que pertencem ou são controladas pela empresa ou instituição, consideradas diretas); Escopo 2 (oriundas da compra de energia, consideradas indiretas); Escopo 3 (outras emissões indiretas, como transporte, geração de resíduos sólidos e efluentes)

\section{Resultados e Discussão}

Escopo 1 - Consumo de gases e combustíveis veiculares: No levantamento do consumo de gases utilizados nos laboratórios da Faculdade de Tecnologia (FT), foi observado que todos eles usam uma quantidade insignificante de GLP e trabalham com outros tipos de gases que não são contabilizados no inventário. O Restaurante Universitário também não utiliza GLP, já que a comida é feita no outro Campus.

Em relação a combustíveis veiculares, a FT possui dois carros, que juntos geraram $0,08 \quad \mathrm{tCO}_{2} \mathrm{e}$ (toneladas métricas de $\mathrm{CO}_{2}$ equivalente) no ano de 2015, segundo cálculos feitos na planilha do GHG Protocol.

Escopo 2 - Energia Elétrica: Utilizando informações sobre gastos de energia elétrica fornecidos pela Diretoria Geral da Administração da Unicamp juntamente com a planilha do GHG Protocol, foi possível obter o valor de emissão de $93,62 \mathrm{tCO}_{2}$ e para este escopo.

Escopo 3 - Geração de resíduos sólidos e transporte e distribuicão: Informações sobre a quantidade de lixo produzido pelo Campus no ano de 2015, foram fornecidas pela Planta Física de Limeira. Como dentro do Campus I, estão presentes a FT e o Colégio Técnico de Limeira (Cotil), foi feito um cálculo com base no número de alunos para se se estimar a quantidade de lixo produzida somente pela $\mathrm{FT}$, devido à dificuldade de se obter as informações necessárias da outra parte do Campus. Assim, foi feita uma caracterização para saber a porcentagem de cada tipo de resíduo, e preencher a planilha do GHG Protocol. A geração de resíduos sólidos teve como resultado um valor de emissão de 55,96 $\mathrm{tCO}_{2} \mathrm{e}$.

Em relação ao transporte e distribuição, foi aplicado um questionário para obter dados sobre tipo de combustível, ano do veículo e distância percorrida diariamente até chegar à faculdade. Foi respondido por $5 \%$ do total de alunos, funcionários e professores que, segundo Da Cruz e D'Avila ${ }^{[1]}$, é uma amostra estatisticamente considerável para este tipo de estudo. Com tais informações e a planilha do GHG Protocol, foi calculado que a parte de transporte e distribuição emitiu $1916,60 \mathrm{tCO}_{2} \mathrm{e}$, sendo a atividade que mais gerou gases de efeito estufa no ano de 2015.

O total de emissão de cada Escopo está apresentado na Tabela 1.

Tabela 1. Emissões geradas na FT em 2015.

\begin{tabular}{|c|c|}
\hline Escopo & $\begin{array}{c}\text { Emissões de } \mathrm{CO}_{2} \text { equivalente } \\
\text { (toneladas métricas) }\end{array}$ \\
\hline 1 & 0,08 \\
\hline 2 & 93,62 \\
\hline 3 & 1972,56 \\
\hline Total & 2066,23 \\
\hline
\end{tabular}

\section{Conclusões}

Analisando os valores obtidos nos três Escopos, é possível perceber que o Escopo 3 é o maior gerador de gases de efeito estufa da $\mathrm{FT}$, somados à geração de resíduos sólidos e transporte e distribuição. Uma forma de neutralizar a emissão é o plantio de árvores que sequestram o $\mathrm{CO}_{2}$ e liberam oxigênio.

\section{Agradecimentos}

À bolsa PIBIC concedida pelo CNPq, à Planta Física de Limeira, à DGA, aos técnicos de laboratórios, aos funcionários responsáveis pela limpeza e às pessoas que responderam os questionários, pelas informações cedidas para que o trabalho pudesse ser realizado.

\footnotetext{
${ }^{1}$ DA CRUZ, F. A.; D’AVILA, S. P. Inventário De Emissões De Gases De Efeito Estufa da Universidade Tecnológica Federal do Paraná - Campus Curitiba - Sede Central e Ecoville. Curitiba, 84p, 2013. Trabalho de Conclusão de Curso - Universidade Tecnológica Federal do Paraná.
} 